\title{
Potentiating Effect of EDTA on Antibiotics Resistant Staphylococcus aureus
}

\author{
Bezalwar $\mathrm{PM}^{*}$, Gomashe $\mathrm{AV}^{2}$ and Gulhane $\mathrm{PA}^{3}$ \\ ${ }^{*}{ }_{1,2,3}$ (Department of Microbiology, S.S.E.S.A's Science College, Congress Nagar,Nagpur-440012 (MS), India).
}

\begin{abstract}
The widespread use of antibiotics is playing a significant role in the emergence of resistant bacteria. It's a need of time to potentiate antibiotics for their activity. Staphylococcus aureus is one of the bacteria acquiring resistance for most of the antibiotics which is a big deal to tackle Staphylococcus aureus infection. The objective of this study is to potentiate the activity of antibiotics against Staphylococcus aureus isolated from skin swab samples. A total of 50 skin swab samples collected resulted into 102 bacterial pathogens which include 70 Staphylococcus aureus. Disc diffusion method was carried out which resulted into 5 antibiotic resistant Staphylococcus aureus. These resistant strains then tested in combination with antibiotic plus EDTA for the study of antibiotic resistance. Five Staphylococcus aureus strains showed resistance against Teicoplanin, Vancomycin and Methicillin. It was observed that some strains which were resistant to the tested antibiotics were become sensitive for that particular antibiotics in combination with EDTA. Combined effect of EDTA with antibiotic potentiated the effect of EDTA on antibiotic resistant Staphylococcus aureus.
\end{abstract}

Keywords: EDTA, Antibiotics, Staphylococcus aureus

\section{Introduction}

Antimicrobial resistance is not new, but the number of resistant organisms, the geographic locations affected by drug resistance, and the breadth of resistance in single organisms are unprecedented and mounting. Diseases and disease agents that were once thought to be controlled by antibiotics are returning in new leagues resistant to these therapies. ${ }^{[1]}$ Antibiotics are used both in treating human disease and in intensive farming to promote animal growth. Both uses may be contributing to the rapid development of antibiotic resistance in bacterial populations. ${ }^{[2]}$

Thus by acquiring the genes which make bacteria resistant to various antibiotics include MRSA (methicillin resistant Staphylococcus aureus) was first detected in Britain in 1961 and is now quite common. The first documented strain with complete $(>16 \mathrm{ug} / \mathrm{ml})$ resistance to vancomycin, termed VRSA (vancomycin resistant Staphylococcus aureus) appeared in the United States in 2002. ${ }^{[3]}$

Ethylene diamine tetra acetic acid (EDTA) is a polyamino carboxylic acid and a colourless, water soluble solid. EDTA is used to bind metal ions in the alternative medical practice of chelation therapy. EDTA have various uses in different fields such as medical, chemical and veterinary; its water solubility and low toxicity made it more friendly so it can use in combination with antibiotics to increase the potency of antibiotics, as well as against the multidrug resistant microorganisms. ${ }^{[4]}$

Farca et al., (1997) studied synergistic effects of the combination of EDTA-tromethamine (EDTA-tris) and three antimicrobial agents (cephaloridine, kanendomycin and enrofloxacin) against resistant Gram positive and Gram negative bacteria. Animals exposed to EDTA tromethamine plus the antibiotics recovered completely within 10 days and were controlled clinically and bacteriologically for 180 days. ${ }^{[5]}$ EDTA-antibiotic combination to control Pseudomonas aeruginosa was done by Mohamed et al., (2006) in which six multidrug resistant strains from patients at Tanta University hospital, Egypt were tested against the the antibiotics with or without the EDTA. It was found out that $70 \%$ of the strains turned from resistant to sensitive. ${ }^{[6]}$

The main objective of the present study was to screen pathogenic Staphylococcus aureus and to study their sensitivity, resistance pattern with special relevance to analyze the effect of EDTA in combination with selected antibiotics.

\subsection{Collection of Clinical Samples:}

\section{Material And Methods:}

Skin swab samples were collected from different pathology laboratories of Nagpur, India from March 2010 to July 2010. This was indeed collected from the patients not responding to routine antibiotic therapy. A total of 102 organisms were isolated from 50 skin swab samples. These isolated bacterial cultures were transferred to microbiology laboratory for further processing. 


\subsection{Identification of Isolated Pathogens:}

The isolated bacterial pathogens were identified on the basis of morphological, cultural and biochemical characteristics and results were compared with Bergey's Manual of Determinative Bacteriology $9^{\text {th }}$ edition. ${ }^{[7]}$ From 102 isolates, 70 were confirmed as Staphylococcus aureus.

\subsection{Preparation of Inoculum:}

A loopful culture of each Staphylococcus aureus was inoculated in $5 \mathrm{ml}$ of sterile nutrient broth tube. The inoculated broth was incubated for 8 hours at $37^{\circ} \mathrm{C}$ and the turbidity was measured using $0.5 \mathrm{McF}$ arland standards.

\subsection{Antibiotic Sensitivity Test:}

All the Staphylococcus aureus were subsequently tested for antibiotic sensitivity patterns by disc diffusion method on Mueller Hinton Agar. ${ }^{[8]}$ The three different antibiotic discs such as Teicoplanin $(30 \mathrm{mcg})$, Vancomycin $(30 \mathrm{mcg})$ and Methicillin $(5 \mathrm{mcg})$ were obtained from Hi-Media Laboratories Pvt. Ltd. Mumbai. The results were interpretated as per Clinical and Laboratory Standards Institute (CLSI) guidelines. ${ }^{[9]}$

\subsection{Selection of Antibiotic Resistant Staphylococcus aureus:}

Out of 70 Staphylococcus aureus strains tested against 3 selected antibiotics, 5 strains not showed zone of inhibition and were considered as antibiotic resistant Staphylococcus aureus. These 5 strains were selected for further study with EDTA.

\subsection{Selection of EDTA Concentrations:}

The preliminary experiments were carried out by using eight different concentrations of EDTA such as $1.95 \mathrm{mM}, 3.9 \mathrm{mM}, 7.8 \mathrm{mM}, 15.6 \mathrm{mM}, 31.2 \mathrm{mM}, 62.5 \mathrm{mM}, 125 \mathrm{mM}$ and $250 \mathrm{mM}$. The $250 \mathrm{mM}$ concentration of the EDTA solution inhibited the bacterial growth therefore the concentration of EDTA used for further study was 250mM. ${ }^{[10]}$

\subsection{Potentiating Effect of EDTA:}

For the study of potentiating effect of EDTA against Staphylococcus aureus strains, the antibiotic discs were applied on the Mueller Hinton agar plate lawned with Staphylococcus aureus culture. A 10 ul of EDTA solution was pippeted onto the each antibiotic disc of the plates. ${ }^{[11]}$ After incubation at $37^{0} \mathrm{C}$ for 24 hours the strains were observed for the formation of zone of inhibition against the tested antibiotics with EDTA.

\section{Results:}

The antibiotic susceptibility test by the disc diffusion method of 70 Staphylococcus aureus was performed against teicoplanin, vancomycin and methicillin. Out of these 70 Staphylococcus aureus isolates only 5 isolates were found to be multidrug resistant. The preliminary experiments were carried out by using eight different concentrations of EDTA such as $1.95 \mathrm{mM}, 3.9 \mathrm{mM}, 7.8 \mathrm{mM}, 15.6 \mathrm{mM}, 31.2 \mathrm{mM}, 62.5 \mathrm{mM}, 125 \mathrm{mM}$ and $250 \mathrm{mM}$. The $250 \mathrm{mM}$ concentration of the EDTA solution inhibited the bacterial growth therefore the concentration of EDTA used for further study was $250 \mathrm{mM}$ (Table 1). Also potentiating activity of EDTA was checked with all antibiotics, it was found that EDTA potentiated activities of teicoplanin, vancomycin and methicillin (Table 2).

\section{Discussion:}

Multi drug resistant Staphylococcus aureus isolate no. 11 showed resistance against teicoplanin, vancomycin, and methicillin. It became sensitive to teicoplanin $(10 \mathrm{~mm})$ and methicillin $(12 \mathrm{~mm})$ when treated with EDTA, but did not show sensitivity against vancomycin. Multi drug resistant Staphylococcus aureus isolate no. 43 showed resistance against teicoplanin, vancomycin and methicillin. It became sensitive to teicoplanin (11 $\mathrm{mm})$ and methicillin $(13 \mathrm{~mm})$ when treated with EDTA $(11 \mathrm{~mm}, 13 \mathrm{~mm})$, but did not show sensitivity against vancomycin. Multi drug resistant Staphylococcus aureus isolate no. 60 showed resistance against teicoplanin, vancomycin and methicillin. It became sensitive to methicillin when treated with EDTA (13mm), but did not show sensitivity against teicoplanin and vancomycin. Multi drug resistant Staphylococcus aureus isolate no. 69 showed resistance against teicoplanin, vancomycin and methicillin. It became sensitive to vancomycin $(11 \mathrm{~mm})$ and methicillin $(13 \mathrm{~mm})$ when treated with EDTA, but did not show sensitivity against teicoplanin. Multi drug resistant Staphylococcus aureus isolate no. 64 showed resistance against methicillin whereas sensitive to teicoplanin $(15 \mathrm{~mm})$ and vancomycin $(15 \mathrm{~mm})$. The sensitivity of multi drug resistant Staphylococcus aureus isolate was found to be increased against teicoplanin $(16 \mathrm{~mm})$ and vancomycin $(16 \mathrm{~mm})$ when treated with EDTA than that of the previous, but did not show sensitivity against methicillin (Table 2). The results were correlated with that of Farca et al., 1994; 1997 in the context of the potentiating effect of EDTA on these antibiotic resistant Staphylococcus aureus. ${ }^{[5]}{ }^{[12]}$ Overall, the result reported in this study showed that the 
combination of antibiotic plus EDTA increases the sensitivity of multi drug resistant Staphylococcus aureus against the selected antibiotics to which previously the organism was resistant. The present study may be fruitful to overcome the problems raised from multi drug resistant pathogens.

\section{References}

[1]. Levy SB, Marshall B. Antibacterial resistance worldwide: causes, challenges and responses. Nature Medicine Supplement 2004; 10: 122-129.

[2]. Khachatourians GG. Agricultural use of antibiotics and the evolution and transfer of antibiotic-resistant bacteria. CMAJ 1998; 159: 1129-1136.

[3]. Bozdogan B, Esel D, Whitener C, Browne FA, Appelbaum PC. Antibacterial susceptibility of a vancomycin resistant Staphylococcus aureus strain isolated at the Hershey Medical Center. Journal of Antimicrobial Chemotherapy $2003 ; 52: 864$.

[4]. Senad KS, Musaddique M. In vitro efficacy testing of EDTA in combination with antibiotics against prominent pathogens. Biosci Biotech Res Comm 2011; 4: 41-46.

[5]. Farca AM, Piromalli G, Maffei F, Re G. Potentiating effect of EDTA-Tris on the activity of antibiotics against resistant bacteria associated with otitis, dermatitis and cystitis. J Small Anim Pract 1997; 38: 243-245.

[6]. Mohamed Z, Amara A, Hussein M. Case by case study using antibiotic EDTA combination to control Pseudomonas aeruginosa. Pak J Pharm Sci 2006; 19: 236-243.

[7]. Collee JG, Marr W. Tests for identification of bacteria and laboratory control of antimicrobial therapy. In: Mackie and McCartney Practical Medical Microbiology Chapter 7 and 8. $14^{\text {th }}$ ed. Collee JG, Fraser AG, Marnion BP, Simmons A, editors. Churchill Livingstone, New York; 1996: 131-151.

[8]. Bauer AW, Kirby WMM, Sherris JC, Turck M. Antibiotic susceptibility testing by a standardized single disc method. Am J Clin Pathol 1996; 45: 493-496.

[9]. CLSI. Performance standards for antimicrobial susceptibility testing: $17^{\text {th }}$ Informational supplement. Approved standard M100-S17, Wayne, USA: Clinical and Laboratory Standards Institute; 2007.

[10]. Chudzik B, Malm A, Rajtar B, Polz dacewicz M. In vitro inhibitory activity of EDTA against planktonic and adherent cells of Candida spp. Annals of Microbiology 2007; 57: 115-119.

[11]. Mueller JH, Hinton J. A protein free medium for primary isolation of the Gonococcus and Meningococcus. Proc Soc Exp Biol Med 1941; 48: 330-333. 12.

[12]. Farca AM, Nebbia P, Re G. Potentiation of antibiotic activity by EDTA-tromethamine against 3 clinically isolated gram-positive resistant bacteria: An in vitro investigation. Vet Res Commun 1994; 18: 1-6.

Table 1: Effect of different concentrations of EDTA on Multi Drug Resistant strains of Staphylococcus aureus

\begin{tabular}{cccccccc}
\hline & \multicolumn{7}{c}{ Zone of Inhibition $(\mathrm{mm})$} \\
\cline { 2 - 8 } MDR SA & \multicolumn{7}{c}{ Concentrations of EDTA } \\
\cline { 2 - 8 } & $1.95 \mathrm{mM}$ & $3.9 \mathrm{mM}$ & $7.8 \mathrm{mM}$ & $15.6 \mathrm{mM}$ & $31.2 \mathrm{mM}$ & $62.5 \mathrm{mM}$ & $125 \mathrm{mM}$ \\
\hline 11 & $\mathrm{NZ}$ & $\mathrm{NZ}$ & $\mathrm{NZ}$ & $\mathrm{NZ}$ & $<10$ & $<10$ & 10 \\
\hline 43 & $\mathrm{NZ}$ & $\mathrm{NZ}$ & $\mathrm{NZ}$ & $\mathrm{NZ}$ & $\mathrm{NZ}$ & 10 & 12 \\
\hline 60 & $\mathrm{NZ}$ & $\mathrm{NZ}$ & $\mathrm{NZ}$ & $\mathrm{NZ}$ & $<10$ & $<10$ & 10 \\
\hline 64 & $\mathrm{NZ}$ & $\mathrm{NZ}$ & $\mathrm{NZ}$ & $\mathrm{NZ}$ & $<10$ & 10 & 11 \\
\hline 69 & $\mathrm{NZ}$ & $\mathrm{NZ}$ & $\mathrm{NZ}$ & $\mathrm{NZ}$ & $<10$ & $<10$ & $<10$ \\
\hline
\end{tabular}

Where, MDR SA= Multi Drug Resistant Staphylococcus aureus, NZ= No Zone of inhibition

Table 2: Potentiating effect of EDTA with antibiotics against MDR strains of Staphylococcus aureus

\begin{tabular}{|c|c|c|c|c|c|c|}
\hline \multirow[b]{2}{*}{ MDR SA } & \multicolumn{6}{|c|}{ Zone of Inhibition in (mm) } \\
\hline & Teicoplanin & $\begin{array}{c}\text { Teicoplanin }+ \\
\text { EDTA }\end{array}$ & Vancomycin & $\begin{array}{c}\text { Vancomycin + } \\
\text { EDTA }\end{array}$ & Methicillin & $\begin{array}{l}\text { Methicillin + } \\
\text { EDTA }\end{array}$ \\
\hline 11 & $\mathrm{NZ}$ & $10 \mathrm{~mm}$ & $\mathrm{NZ}$ & $\mathrm{NZ}$ & $\mathrm{NZ}$ & 12 \\
\hline 43 & $\mathrm{NZ}$ & 11 & $\mathrm{NZ}$ & $\mathrm{NZ}$ & $\mathrm{NZ}$ & 13 \\
\hline 60 & $\mathrm{NZ}$ & NZ & $\mathrm{NZ}$ & NZ & $\mathrm{NZ}$ & 13 \\
\hline 64 & 15 & 16 & 15 & 16 & $\mathrm{NZ}$ & NZ \\
\hline 69 & NZ & NZ & NZ & 11 & $\mathrm{NZ}$ & 13 \\
\hline
\end{tabular}

Where, MDR SA= Multi Drug Resistant Staphylococcus aureus, NZ= No Zone of inhibition 